\title{
Frontières
}

\section{GREIF, Hans-Jürgen, La colère du faucon, Québec, L'instant même, 2013, 285 p.}

\section{Claire Varin}

Volume 25, numéro 2, 2013

URI : https://id.erudit.org/iderudit/1024950ar

DOI : https://doi.org/10.7202/1024950ar

Aller au sommaire du numéro

\section{Éditeur(s)}

Université du Québec à Montréal

ISSN

1916-0976 (numérique)

Découvrir la revue

Citer ce compte rendu

Varin, C. (2013). Compte rendu de [GREIF, Hans-Jürgen, La colère du faucon, Québec, L’instant même, 2013, 285 p.] Frontières, 25(2), 150-151.

https://doi.org/10.7202/1024950ar

Ce document est protégé par la loi sur le droit d'auteur. L'utilisation des services d'Érudit (y compris la reproduction) est assujettie à sa politique d'utilisation que vous pouvez consulter en ligne.

https://apropos.erudit.org/fr/usagers/politique-dutilisation/
Cet article est diffusé et préservé par Érudit.

Érudit est un consortium interuniversitaire sans but lucratif composé de l’Université de Montréal, l'Université Laval et l'Université du Québec à Montréal. Il a pour mission la promotion et la valorisation de la recherche. https://www.erudit.org/fr/ 
GREIF, Hans-Jürgen

\section{La colère du faucon}

Québec, L'instant même, 2013, 285 p.

\section{Claire Varin}

Écrivaine

Juste avant La colère du faucon, Hans-Jürgen Greif observait avec une lucidité empreinte de tendresse la vie des personnes âgées en centre d'hébergement (Le temps figé, 2012, en tandem avec Guy Boivin). L'ouroboros se mordant la queue, comme on le sait ou pas, c'est maintenant l'enfance blessée, après la vieillesse, qu'il nous offre dans son huitième roman, aux accents autobiographiques. Une enfance dans un lieu sauf erreur jamais foulé par la littérature québécoise: la Sarre, territoire frontalier et protectorat français redevenu allemand dans les années 1950. L'auteur y est né pendant la Seconde Guerre mondiale. Nous survolons ce paysage méconnu en accompagnant dans son apprentissage le petit oiseau en colère de l'histoire, un garçon nommé Falk (faucon en allemand). Il appartient à la famille Bachmann dont le père, affecté au service des renseignements, s'affairait dans Paris occupé, à titre d'officier de la Wehrmacht.

Qui dit guerre, dit mort. Elle se reflète dans les yeux rêveurs de Falk qui, avec son frère aîné, est témoin des bombardements alliés sur la capitale Sarrebruck, où tente de s'approvisionner leur mère pendant que le père est absent. Nous sommes en 1945, sur fond de fin de guerre: la famine sévit à tel point que les survivants en sont réduits à accepter le troc. Dans leurs explorations des ruines de la ville, les jeunes peuvent tomber sur des squelettes en uniforme ou en civil. La mort est partout.

Un an après I'armistice, Falk reverra pour son malheur le visiteur nocturne, apparu pendant la guerre dans la maison familiale: I'«étranger» avait alors menacé sa mère dans les bras de laquelle il était blotti, et tiré sur sa tresse blonde, lui renversant la tête vers l'arrière; I'enfant s'était agrippé au cou maternel pour se protéger de ce qu'il apprendrait à bien connaître, la haine.

L'inquiétant personnage est revenu pour de bon, et on lui annonce qu'il est son père. Dès leur première rencontre cette nuit-là de 1944, germe chez Falk une méfiance viscérale à l'endroit de l'homme au regard acide. Son «soi-disant» père le déteste parce que Falk, au contraire du fils aîné, ne lui ressemble pas... Viennent ensuite sous forme de maltraitance des morts quotidiennes, invisibles, subies par l'enfant.

Et c'est ainsi que le collectif reflète en miroir l'individuel: tandis que I'Allemagne est à genoux et travaille à sa reconstruction, le père œuvre à son relèvement personnel - empressé de regagner du pouvoir social et un prestige perdu lors de la défaite allemande, et tandis que la mère s'active en secret à se bâtir une carrière d'archéologue, Falk apprend à se relever du despotisme paternel. Il affrontera la bête à sa manière lors 
de séances où son agresseur se targue d'enseigner des matières à son cadet dont il a fini par se rendre compte qu'il n'est pas stupide après tout, que ça vaut le coup de lui entrer quelque chose dans le crâne au propre comme au figuré : «Quand la mère sort de la pièce pour préparer le souper, I'homme peut brutaliser l'enfant à loisir. Il connaît des façons de lui faire mal sans laisser de marques: la phalange centrale du majeur frappe l'arrière du crâne de Falk, assez fortement pour que l'enfant hoche la tête dans un geste absurde. Il a l'air d'être d'accord avec les méthodes d'enseignement du pédagogue alors qu'il est plongé en pleine panique. Il sait qu'en l'absence de sa mère, il subira toutes sortes de sévices. » Ça, c'est pour les leçons de mathématiques, et, pour les séances de piano, non seulement une fausse note mérite un coup derrière la tête mais une «oreille tordue, ou les cheveux tirés sur les tempes, ou le pouce et l'index enfoncés dans les épaules, à côté des clavicules, ou encore un coup de poing sur le genou ». La mère sait, mais ne dit rien.

Les petites morts viennent là où on les attend le moins : la mère aimante et aimée, un jour, frappe Falk, pour «la première et la dernière fois» parce qu'il lui a menti et que le mensonge lui répugne: «Quelque chose vient de se briser, il a senti et entendu quand cela s'est produit. Une maison de verre, une construction sophistiquée est réduite en un tas de débris, étincelants, tranchants, dangereux. Ne pas toucher à ça, ne plus I'approcher, elle. Devenir neutre en formulant les mots justes et les phrases appropriées, rien que le nécessaire. Cacher ses pensées, ses soucis, ses préoccupations [...]. Elle ne sera plus sa mère. » Mais elle le restera jusqu'à sa mort prématurée.

Qui dit mort, dit vie aussi. En contrepoids à la figure paternelle, mortifère, celle du grand-père maternel de Falk, douée de vie. Vivantes aussi sont l'écriture fluide, précise et efficace ainsi que la finesse d'observation de l'auteur de La colère du faucon, oiseau racé dans le ciel du Québec.

\section{WITTKOP Gabrielle}

\section{The Necrophiliac}

Traduit en anglais par Don Bapst

Toronto, ECW Press, 2011, 91 p.

\section{Les départs exemplaires}

Paris, Verticales, 2012, 229 p.

\section{Patrick Bergeron}

Professeur agrégé, Département d'études françaises, Université du Nouveau-Brunswick

En décembre 2012, dix ans s'étaient écoulés depuis la mort de Gabrielle Wittkop, cette romancière née à Nantes en 1920 et installée jusqu'à la fin de sa vie en Allemagne, où elle collaborait aux pages culturelles de la Frankfurter Allgemeine Zeitung. De tous les écrivains fascinés par la mort, 